\title{
Effects of Snoezelen Therapy on Stress, Anxiety, Depression, and Quality of Life of College Students with Game Addiction
}

\author{
Ji-Yun Lim, Jong-Hoon Kim, Seul-Mi Lee, Woo-Hyuk Jang \\ Department of Occupational Therapy, College of Health Science, Kangwon National University, Samcheok, Republic of Korea
}

Purpose: Despite the existence of Snoezelen method, there is no case of researching the effects on game addiction. Therefore, this study aims to investigate the effects of Snoezelen therapy on stress, depression, anxiety and quality of life of college students who overuse computer games or mobile phone games.

Methods: Eight students who responded to spend more than 30 hours of computer or mobile phone games in the selection questionnaire were recruited (The total respondents were 224 students). Students were randomly assigned to either the study group (4 students) or the control group (4 students). Stress (Korean version of Perceived Stress Scale, K-PSS), depression (Korean Screening Tool for Depression Disorders, K-DEP), Anxiety (Korean Beck Anxiety Inventory, K-BAI) and quality of life (Short Form Health Survey version 2 [SF-36]) were assessed three times (before intervention [pre], post-3 weeks [post 1], post-6 weeks [post 2]).

Results: First, the study group $(-4.75 \pm 3.86)$ and control group $(1.00 \pm 2.71)$ showed significant difference $(p<0.05)$ in the analysis of score changes between pre-test and test at 6 weeks (post 2) for K-DEP. Next, pre-test and test at 3 weeks of intervention (post 1) for KBAl showed significant difference $(p<0.05)$ in the study group $(-2.50 \pm 1.91)$ and control group $(2.25 \pm 2.99)$. In addition, pre-test and test at 6 weeks (post 2) showed significant difference $(p<0.05)$ for the study group $(-3.00 \pm 1.51)$ and control group $(4.75 \pm 6.24)$.

Conclusion: The study confirmed the possibility of Snoezelen therapy as a therapy method to induce effective responses in stress, depression, anxiety, and quality of life of college students with game addiction.

Keywords: Snoezelen therapy, Game addiction, Mental health, Quality of life, Student

\section{INTRODUCTION}

Internet has brought sensational change that allowed access to various information and easy interactions with many people. ${ }^{1}$ Internet possess positive functions such as sharing information, hobbies, education, and stress relief, but there is an increase of dysfunctions due to over use. ${ }^{2}$ According to '2015 Report on Internet Overindulgence” by National Information Society Agency, $6.8 \%$ of internet users with the age range from 3 years to 59 years showed internet overindulgence, and 54.6\% of this group were played online games. ${ }^{3}$ Additionally, personal problems such as unemployment and social issues such as crime due to overindulgence of internet games are frequently reported. ${ }^{4}$ Following this social concerns, American Psychiatric Association have added internet gaming disorder (IGD) as a diagnostic criteria for research in Diagnostic and Statistical Manual of
Mental Disorders 5th edition (DSM-5). ${ }^{5}$

There are many studies that investigated the adverse effects of game addictions. ${ }^{6-11}$ In a study on children, game addiction resulted in indirect effects of anxiety, depression, and stress. ${ }^{6}$ In addition, game addiction showed positive correlation between children's anxiety and depression, ${ }^{7}$ and higher level of addiction demonstrated greater aggression. ${ }^{8}$ Studies conducted on adolescents also demonstrated adverse effects of game addiction. ${ }^{9-11}$ One study reported that game addiction had negative effects on depression and emotional control, ${ }^{9}$ and demonstrated high correlations among depression, anxiety, adolescent stereotypical behaviors, and impulsive behaviors. ${ }^{10}$ Additionally, another study showed negative correlations between the level of game addiction and quality of life. ${ }^{11}$

Along with the studies on the adverse effects of game addiction, there are many reports on different therapeutic methods. ${ }^{12-19}$ In studies with 
children, play-centered cognitive therapy was used to reduce game addiction, ${ }^{12}$ and music therapy also showed effectiveness in reducing game addiction ${ }^{13}$ In another study, self-control training was used to increase the ability to control self and resulted in decreasing game addiction of children. ${ }^{14}$ Another study reported in decreasing game addiction by using Scratch Programming, which is an Educational Programing Language (EPL). ${ }^{15}$ Additionally, group art therapy on children showed effectiveness in decreasing aggressiveness and enhancing the ability to control emotions resulting from overindulgence of internet gaming. ${ }^{16}$ As for therapy for adolescents, therapy based on trans-theoretical model (TTM) that deals with the recovery process of problematic behaviors, music therapy, and group counseling programs using nature such as forest healing are reported to reduce depression, anxiety, and addiction levels..$^{17}$ Aerobic exercises are also reported to effectively increase quality of life of adolescents. ${ }^{18}$ Finally, a study on university students reported that horticulture therapy was effective in self-control and decreasing anxiety and depression. ${ }^{19}$

Snoezelen come from two German words 'snuffelen' which means sniffing and 'doezelen' which means dozing, and it is constructed to embody the concept of multisensory environment or multisensory space. ${ }^{20}$ Snoezelen method has received attention for many psychological stabilization therapies for stress, anxiety, and much more. ${ }^{21-25}$ The purpose of Snoezelen therapy is to induce comfort and positive responses via pleasant stimulations in good environments, ${ }^{21}$ and there are many studies that report the use of various stimuli such as optical fibers, scented candles, and music simultaneously during Snoezelen therapy. ${ }^{22}$ It started out as a leisure activity for people with disabilities, and eventually helped researchers understand the environment from the stimulation methods that the people with disabilities experience. ${ }^{23}$ Snoezelen not only increase the quality of life through the enjoyment of leisure, ${ }^{24}$ but also serves the purpose of therapy by decreasing negative or antisocial behaviors, increasing sociality and interest of the outer world, and improving personal hygiene habits. ${ }^{25}$ In the same way, many studies have been conducted and demonstrated other therapeutic effects other that psychological stabilization. ${ }^{26-28}$ Studies on children with intellectual and developmental disabilities and people with dementia demonstrated gradual decreases in self stimulating behaviors, problematic behaviors, and abnormal behaviors. ${ }^{26}$ Likewise, a study on university students has shown potentially significant therapeutic approach for improvement of emotional status and stress management and alleviation. ${ }^{27}$ Alongside with these studies, one study demonstrated the significant decrease in problematic behaviors through relaxation using Snoezelen. ${ }^{28}$ One characteristic of Snoezelen therapy is that this method promotes psychological stabilization by allowing the participants to voluntarily engage and enjoy the therapeutic process, rather that learning certain skills. ${ }^{29}$ Furthermore, there is a report that provision of various sensory stimulations yielded positive effects by affecting the autonomous nervous responses. ${ }^{27}$ Overall, there are many reports on the effects of Snoezelen therapy, but there are no studies of Snoezelen and the effects on game addiction.

Therefore, this study aims to investigate the effects of Snoezelen therapy on stress, depression, anxiety and quality of life of university students who overuse computer games or mobile phone games.

\section{METHODS}

\section{Participants}

The participants of this study are colleges students of K university in Samcheok City, Kangwon Province, in their 20's, and who responded to spend more than 30 hours of computer or mobile phone games in the selection questionnaire. ${ }^{5}$ Among the 224 respondents of the questionnaire, 9 participants, who have met the inclusion criteria for the study and gave consent for participation in the study, were randomly assigned. Five participants were assigned as study group and four were assigned to control group. However, one participant from the study group dropped out from the study due to personal reasons. Therefore, the study included 4 participants for the study group and 4 participants for the control group. Before conducting the study, the researchers explained the purpose of the study based on the ethical standards of Declaration of Helsinki. All study participants were provided with a description of the study and were made aware of their right to withdraw at any stage of the study. Written informed consent was obtained from the participants. All data were stored anonymously

\section{Measurements}

\section{1) Korean version of Perceived Stress Scale (K-PSS)}

This assessment tool was initially developed by Cohen et al. in order to measure the level of subjectively perceived stress in everyday living, ${ }^{30}$ and Cohen and Williamson ${ }^{31}$ modified the scales to a shorter version through factor analysis. This study used the translated version of perceived stress scale of Cohen and Williamson by Lee (reliability $=0.83$ ). ${ }^{32}$ This tool has 10 items each asking how often one experienced the stress in each items in the past month. The response is in a 5 point Likert scale, where 0 means 'Never experienced' and 4 means 'Experienced very often'. Some items (4, 
5,7 , and 8) were scored reversely, thereby making higher score meaning higher level of perceived stress. ${ }^{32}$

\section{2) Korean Screening Tool for Depression Disorders (K-DEP)}

This is an assessment tool was developed to secure sensitivity and specificity of the items by collecting existing depression measurement tools. KDEP is a self-reported test where the responses are elicited from the experiences of each items for the past two weeks. It consists 12 total items and each items are marked on a 5-point scale ranging from 0 to 4 , where 0 is 'Never' and 4 is 'Always'. Total score ranges from 0 to 48 points and higher score means higher level of depression. Specifically, 11 diagnostic criteria for major depression disorder including depressed feeling, decreased interest, psychomotor agitation or delay, fatigue, sense of worthlessness, difficulty in concentrating or indecisiveness, suicide accident or attempt, anxiety, hopelessness, change in appetite or body weight, and change in sleeping patterns are included (Cronbach's alpha $=0.99) .{ }^{33}$

\section{3) Korean Beck Anxiety Inventory (K-BAI)}

This tool was developed by Beck et al. ${ }^{34}$ and translated by Kwon..$^{35}$ This Korean version of Beck Anxiety Inventory was used to measure the anxiety level of the adults. K-BAI is constructed with 21 items and each item are responded on a 4-point scale ranging from 0 to 3 , where 0 means 'Not at all' and 3 means 'Severely'. Total score ranges from 0 to 63, and higher score means higher level of anxiety. Scores between 0 to 9 means normal range, 10 to 18 means mild anxiety, 19 to 29 means moderate anxiety, and score over 30 means severe level of anxiety $($ reliability $=0.84) .{ }^{35}$

\section{4) Short Form Health Survey version 2 (SF-36)}

SF-36 is a self-reporting type questionnaire developed by Ware and Sherbourne in order to determine the quality of life related to health. ${ }^{36}$ This study used the SF-36 version 2 that modified limitations from the previous version (reliability $=0.8-0.95) .{ }^{37}$ The questionnaire consists of 19 items for functional status, 11 items for well-being, and 6 items for overall evaluation of health, where each items that was selected by the respondents have been recorded in the computer program by the researchers. Calculated score is shown in two different domains of Physical Component Summary (PCS) and Mental Component Summary (MCS). PCS describes physical function, physical role, body pain, and general health, and MCS describes vitality, social functioning, emotional role, and mental health. ${ }^{38}$ Higher score in each items means higher level of health related quality of life. ${ }^{36}$

\section{Study design and process}

\section{1) Study design}

This study took place in a Snoezelen room where only the study groups received the intervention. The control group stayed in the Snoezelen room for the same amount of time at a different time schedule with the study group. All the study and control groups were assessed before the intervention (pre) and two after the intervention assessments were made (post 1,2). The design of this study is shown in Figure 1.

\section{2) Study process}

This study took place for 6 weeks from October 28, 2019 to December 8. Each session lasted 30 minutes, twice a week, for a total of 18 sessions. The study group received Snoezelen optical fibers, classical music, and the room temperature of $24^{\circ} \mathrm{C}$ for visual, auditory, and temperature sensory input. ${ }^{22}$ The participants of the control group were assigned to the same place where the study group received the intervention, but no sensory stimulation was provided. Korean version of the Perceived Stress Scale, Korean Screening Tool for Depression Disorders, Korean Beck Anxiety Inventory, and SF-36 (Version 2 of Short Form 36 Health Survey) was conducted to before the intervention test (pre); the same assessments were made twice during the third and sixth week (post1, post2, respectively) of the intervention period. Additionally, times for playing games were set

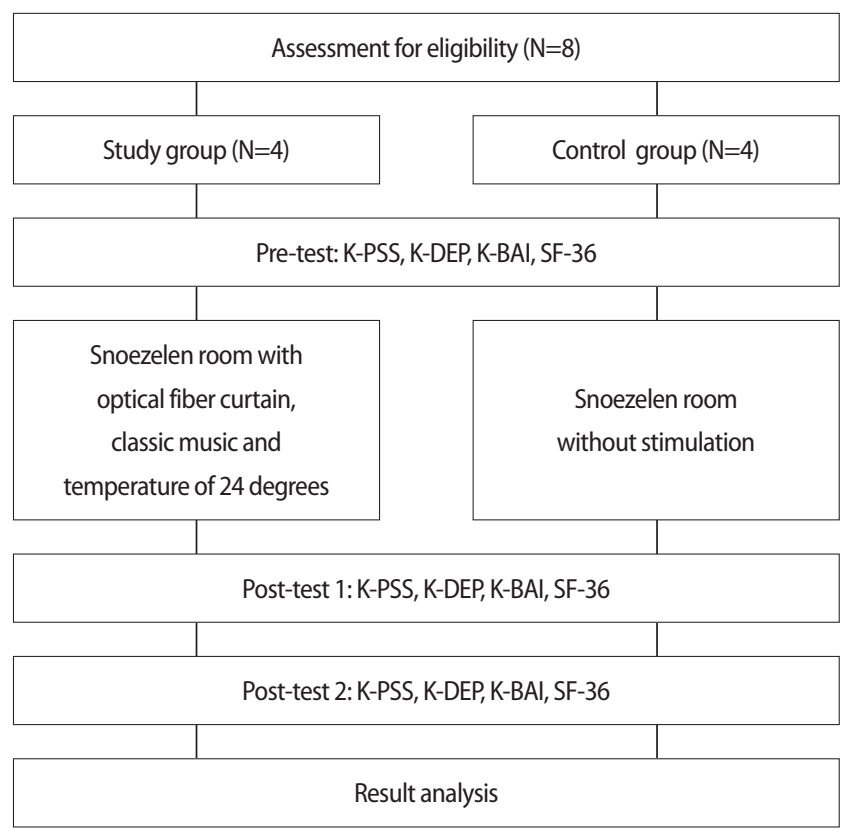

Figure 1. Flow diagram study process.

K-PSS: Korean Version of the Perceived stress scale, K-DEP: Korean Screening Tool for Depression Disorders, K-BAl: Korean Beck Anxiety Inventory, SF-36: Version 2 of Short Form 36 Health Survey. 
freely for both the study and control groups during the study period. The Scene of Snoezelen therapy is shown in Figure 2.

\section{Data analysis}

Data analysis was made using Statistical Package for the Social Sciences 25

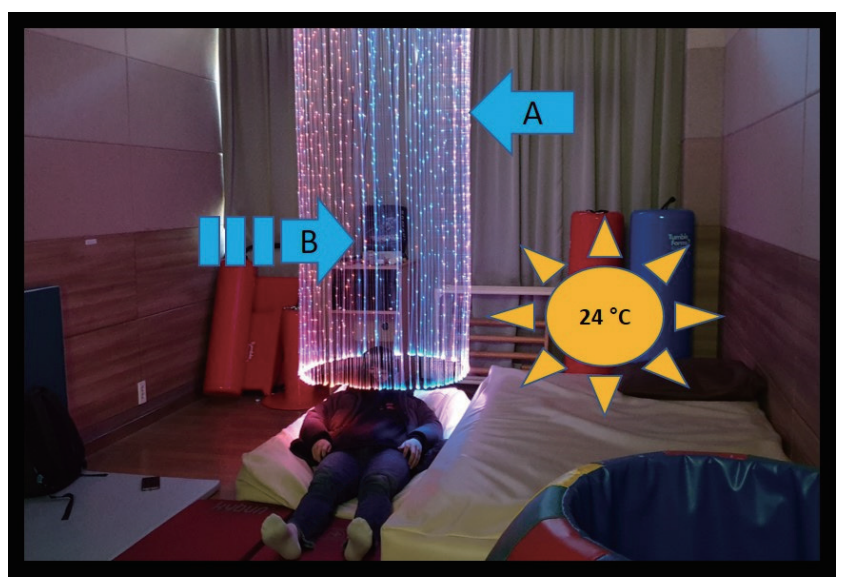

Figure 2. Snoezelen therapy scene.

A: Optic fiber, B: Audio for classic music, The temperature was applied at 24 degrees $\left({ }^{\circ} \mathrm{C}\right)$.
(SPSS, IBM). General characteristics and homogeneity test were made through frequency analysis and Mann-Whitney U test. Sex, siblings, religion, type of residence, and existence of a sexual partner were analyzed using chi-squared test. The amount of change within the groups before and after the test were analyzed using Wilcoxon signed rank test, and between the groups analyzation was made using Mann-Whitney U test. All statistical significance level $\alpha$ in this study was set to 0.05 .

\section{RESULTS}

\section{General characteristics between groups and homogeneity test}

General characteristics of the groups are shown in Table 1 and there were no statistically significant differences of the groups before the intervention (Table 1).

\section{Comparison of mean values within groups before and after the interventions}

There were no significant differences in all tests. However, in Korean version of Perceived Stress Scale (K-PSS), Korean Screening Tool for Depres-

Table 1. General characteristics of the participants and homogeneity test results

\begin{tabular}{|c|c|c|c|}
\hline Characteristics & Study group $(n=4)$ & Control group $(n=4)$ & $\mathrm{p}$ \\
\hline \multicolumn{4}{|l|}{ Gender } \\
\hline Male & 4 & 3 & 0.285 \\
\hline Female & 0 & 1 & \\
\hline Age (yr) & 24 & 24.5 & 0.215 \\
\hline Time playing games $(\mathrm{wk})(\mathrm{hr})$ & 32.5 & 40 & 0.850 \\
\hline Average sleeping time on weekdays (hr) & 6.5 & 7.25 & 0.222 \\
\hline Average sleeping time on weekends (hr) & 8.75 & 1.05 & 0.178 \\
\hline \multicolumn{4}{|l|}{ Type of residence } \\
\hline Dormitory & 4 & 2 & 0.091 \\
\hline non-dormitory (away from family) & 0 & 2 & \\
\hline \multicolumn{4}{|l|}{ Sexual partner } \\
\hline In a relationship & 1 & 1 & 0.285 \\
\hline None & 3 & 3 & \\
\hline \multicolumn{4}{|l|}{ Siblings } \\
\hline Brother & 2 & 3 & 0.504 \\
\hline Sister & 1 & 1 & \\
\hline $\mathrm{K}-\mathrm{PSS}(\mathrm{M} \pm \mathrm{SD})$ & $20.00 \pm 3.02$ & $17.50 \pm 2.73$ & 0.770 \\
\hline $\mathrm{K}-\mathrm{DEP}(\mathrm{M} \pm \mathrm{SD})$ & $8.00 \pm 4.04$ & $4.00 \pm 0.40$ & 0.884 \\
\hline $\mathrm{K}-\mathrm{BAI}(\mathrm{M} \pm \mathrm{SD})$ & $8.75 \pm 2.92$ & $5.25 \pm 1.65$ & 0.561 \\
\hline \multicolumn{4}{|l|}{ SF-36 } \\
\hline $\mathrm{MCS}(\mathrm{M} \pm \mathrm{SD})$ & $69.84 \pm 15.33$ & $63.59 \pm 6.57$ & 0.248 \\
\hline $\mathrm{PCS}(\mathrm{M} \pm \mathrm{SD})$ & $67.88 \pm 12.31$ & $74.84 \pm 10.37$ & 0.386 \\
\hline
\end{tabular}

$\mathrm{M} \pm$ SD: mean \pm standard deviation, K-PSS: Korean Version of the Perceived stress scale, K-DEP: Korean Screening Tool for Depression Disorders, K-BAl: Korean Beck Anxiety Inventory, SF-36: Version 2 of Short Form 36 Health Survey.

${ }^{*} p<0.05$. 
Table 2. Comparison of mean values within groups before and after the interventions

\begin{tabular}{|c|c|c|c|c|c|c|c|c|c|}
\hline \multirow{2}{*}{\multicolumn{4}{|c|}{ Categories }} & \multirow{2}{*}{\multicolumn{2}{|c|}{$\frac{\text { Study group }}{\mathrm{M} \pm \mathrm{SD}}$}} & \multirow{3}{*}{$\begin{array}{c}P \\
0.465\end{array}$} & \multirow{2}{*}{\multicolumn{2}{|c|}{$\frac{\text { Control group }}{\mathrm{M} \pm \mathrm{SD}}$}} & \multirow{3}{*}{$\begin{array}{c}P \\
0.465\end{array}$} \\
\hline & & & & & & & & & \\
\hline \multirow[t]{3}{*}{ K-PSS } & & Pre & Post 1 & $20.00 \pm 3.02$ & $17.50 \pm 2.6$ & & $17.50 \pm 2.73$ & $19.00 \pm 1.08$ & \\
\hline & & Post 1 & Post 2 & $17.50 \pm 2.6$ & $18.25 \pm 1.88$ & 0.854 & $19.00 \pm 1.08$ & $18.00 \pm 2.91$ & 0.854 \\
\hline & & Pre & Post 2 & $20.00 \pm 3.02$ & $18.25 \pm 1.88$ & 0.751 & $17.50 \pm 2.73$ & $18.00 \pm 2.91$ & 0.751 \\
\hline \multirow[t]{3}{*}{ K-DEP } & & Pre & Post 1 & $8.00 \pm 4.04$ & $7.50 \pm 5.95$ & 0.715 & $4.00 \pm 0.40$ & $3.00 \pm 1.78$ & 0.715 \\
\hline & & Post 1 & Post 2 & $7.50 \pm 5.95$ & $3.25 \pm 2.92$ & 0.285 & $3.00 \pm 1.78$ & $5.00 \pm 1.00$ & 0.285 \\
\hline & & Pre & Post 2 & $8.00 \pm 4.04$ & $3.25 \pm 2.92$ & 0.066 & $4.00 \pm 0.40$ & $5.00 \pm 1.00$ & 0.066 \\
\hline \multirow[t]{3}{*}{ K-BAl } & & Pre & Post 1 & $8.75 \pm 2.92$ & $6.25 \pm 3.57$ & 0.102 & $5.25 \pm 1.65$ & $7.50 \pm 3.07$ & 0.102 \\
\hline & & Post 1 & Post 2 & $6.25 \pm 3.57$ & $5.75 \pm 3.11$ & 0.564 & $7.50 \pm 3.07$ & $10.00 \pm 4.02$ & 0.564 \\
\hline & & Pre & Post 2 & $8.75 \pm 2.92$ & $5.75 \pm 3.11$ & 0.063 & $5.25 \pm 1.65$ & $10.00 \pm 4.02$ & 0.063 \\
\hline \multirow[t]{6}{*}{ SF-36 } & M & Pre & Post 1 & $69.84 \pm 15.33$ & $65.89 \pm 13.55$ & 1.000 & $63.59 \pm 6.57$ & $69.53 \pm 6.80$ & 1.000 \\
\hline & C & Post 1 & Post 2 & $65.89 \pm 13.55$ & $89.92 \pm 2.66$ & 0.144 & $69.53 \pm 6.80$ & $75.55 \pm 5.17$ & 0.144 \\
\hline & $S$ & Pre & Post 2 & $69.84 \pm 15.33$ & $89.92 \pm 2.66$ & 0.144 & $63.59 \pm 6.57$ & $75.55 \pm 5.17$ & 0.144 \\
\hline & $P$ & Pre & Post 1 & $67.88 \pm 12.31$ & $71.17 \pm 7.72$ & 0.465 & $74.84 \pm 10.37$ & $74.30 \pm 9.43$ & 0.465 \\
\hline & C & Post 1 & Post 2 & $71.17 \pm 7.72$ & $85.31 \pm 2.96$ & 0.144 & $74.30 \pm 9.43$ & $77.26 \pm 10.31$ & 0.144 \\
\hline & S & Pre & Post 2 & $67.88 \pm 12.31$ & $85.31 \pm 2.96$ & 0.273 & $74.84 \pm 10.37$ & $77.26 \pm 10.31$ & 0.273 \\
\hline
\end{tabular}

$\mathrm{M} \pm$ SD: mean \pm standard deviation, pre: pre-test, post 1: at 3 weeks, post 2: at 6 weeks, K-PSS: Korean Version of the Perceived stress scale, K-DEP: Korean Screening Tool for Depression Disorders, K-BAl: Korean Beck Anxiety Inventory, SF-36: Version 2 of Short Form 36 Health.

${ }^{*} \mathrm{p}<0.05$.

sion Disorders (K-DEP), and Korean Beck Anxiety Inventory (K-BAI), the study group showed a tendency of decrease compared to the control group. In addition, sub-items Mental Component Summary (MCS) and Physical Component Summary (PCS) of Version 2 of Short Form 36 Health Survey (SF-36) showed a tendency of increase (Table 2).

\section{Comparison of changes between the groups by sections before and after the intervention}

First, the study group $(-4.75 \pm 3.86)$ and control group $(1.00 \pm 2.71)$ showed significant difference in the analysis of score changes between pre-test and test at 6 weeks (post 2) for K-DEP $(\mathrm{p}<0.05)$. Next, pre-test and test at 3 weeks of intervention (post 1) for K-BAI showed significant difference in the study group $(-2.50 \pm 1.91)$ and control group $(2.25 \pm 2.99)(\mathrm{p}<0.05)$. In addition, pre-test and test at 6 weeks (post 2) showed significant difference for the study group $(-3.00 \pm 1.51)$ and control group $(4.75 \pm 6.24)(\mathrm{p}<0.05)$. There was no significant difference in the test areas. However, there was a tendency of decrease in K-PSS. Additionally, there was a tendency of increase in the sub-areas of SF-36, MCS and PCS (Figure 3).

\section{DISCUSSION}

This study investigated the effects of Snoezelen therapy on stress, anxiety, depression, and quality of life of university students who overindulge computer games or mobile phone games. The participants of the study were students of K university in Samcheok City, Kangwon Province, who are in their 20's, and played computer or mobile phone games for more than 30 hours a week. 8 students who were included in the study were randomly assigned to study and control groups. During the study period, the two groups played games autonomously without any restrictions. Firstly, Korean version of Perceived Stress Scale (K-PSS) was used to determine the effects on stress and Korean Screening Tool for Depression Disorders (K-DEP) to determine the effects on depression. Likewise, Korean Beck Anxiety Inventory (K-BAI) was used to investigate the effects no anxiety and Version 2 of Short Form 36 Health Survey (SF-36) was used to investigate the effects on quality of life.

When the scores before and after the interventions within the control and study groups are compared, both groups did not show statistically significant mean values for K-PSS, K-DEP, and K-BAI. However, the study group showed a decrease in the scores when compared to the control group, thereby demonstrating that stress, depression, and anxiety domains have improved. In addition, both groups also did not reveal statistically significant mean values for SF-36, but the scores of the study group showed increase when compared with the control group. Therefore, quality of life domain has improved. When the changes of scores within control 


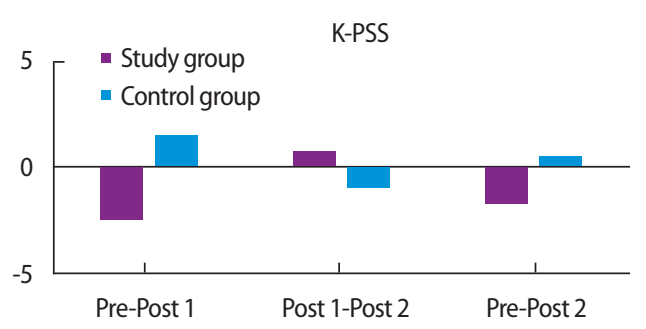

K-DEP
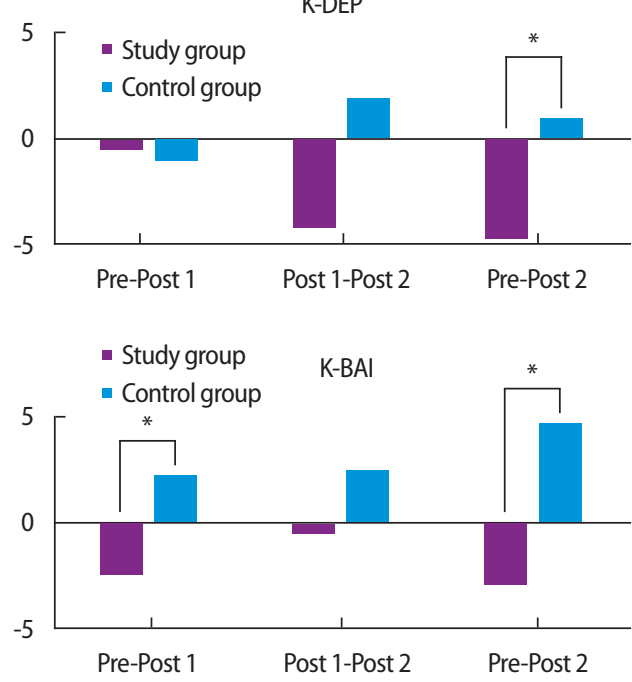

and study groups are compared, pre-test and test at 6 weeks (post 6) of KDEP showed statistically significant difference, and the change in pre-test and test at 3 weeks (post 1) and the change in pre-test and test at 6 weeks (post 2) of K-BAI showed statistically significant differences. Therefore, the intervention has significant effects on decreasing depression and anxiety. On the other hand, K-PSS and SF-36 did not show and statistically significant difference. However, K-PSS and SF-36 demonstrated positive features, where there was more decrease in scores compared to the control group. These results could illustrate the positive effects of quality of life. One interesting finding is that depression and anxiety have decreased and quality of life has increased in before and after the intervention scores within the control group. Although the game is having an adverse effect on one's life, it can be inferred as a result of the transient sense of accomplishment attained through simple immersion without realization. ${ }^{39}$

Snoezelen therapy method used in this study was developed in The Netherlands in $1977,{ }^{40}$ and includes tools that stimulate tactile, visual, olfactory, auditory, vestibular, and proprioceptive senses. ${ }^{41}$ Snoezelen therapy method in the early period was provided as a part of leisure and recreation. However, therapeutic effects have been verified, and are currently used widely by caregivers and professionals. ${ }^{42}$ Existing studies have demonstrated the major effects of psychological relaxation and stabilization,

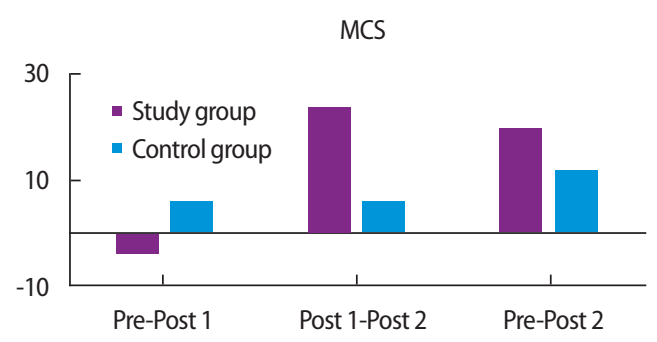

PCS

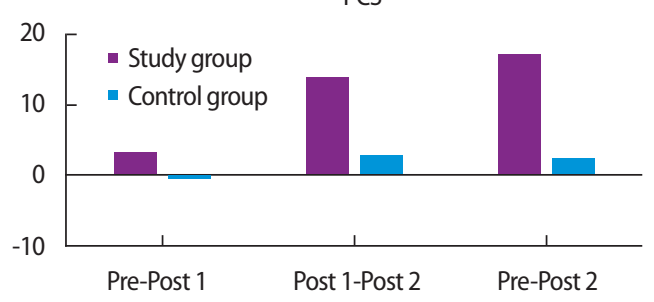

Figure 3. Mean score changes between control and study groups. ${ }^{*} \mathrm{p}<0.05$. K-PSS: Korean Version of the Perceived stress scale, K-DEP: Korean Screening Tool for Depression Disorders, K-BAl: Korean Beck Anxiety Inventory, SF-36: Version 2 of Short From 36 Health Survey.

and stress relief. Furthermore, there are reports that Snoezelen promotes cognitive and social functions of people with dementia and children with intellectual disabilities through therapeutic effects such as relaxation, peaceful emotions, and decreased anxiety. ${ }^{41}$ In the study on children with intellectual and developmental disabilities and people with dementia, Snoezelen application gradually decreased self-stimulating, problematic, and abnormal behaviors, ${ }^{26}$ and it has positive effects on emotional and psychological status. ${ }^{27,28}$ In the study on students with learning disabilities, Snoezelen had effects on improving quality of life through the provision of enjoyable leisure. ${ }^{24}$ The existing studies on university students demonstrated significant effects on stress, anxiety, depression, anger, vitality, fatigue, and sense of confusion. ${ }^{28,43}$ Furthermore, there is a report that there is a significant result in decreasing stress and depression of college students when Snoezelen was applied. ${ }^{43,44}$ This study showed statistically significant decrease in stress and depression of university students who are game addicts when compared with the control group, and it demonstrates similar results of existing studies. Judging from these results, it could be speculated that Snoezelen therapy had positive effects on psychological stabilization by stimulating the autonomous nervous system. ${ }^{27}$ Moreover, the fact that voluntary participation was promoted only through provision of various sensory stimulations without the burden of learning specific 
skills and this pleasant state may have had an important effect on the participants' stability. ${ }^{29}$ Moreover, this is the first study conducted to investigate the effects of Snoezelen on stress, depression, anxiety and quality of life of university students who are addicted to computer or mobile phone games.

The first limitation of this study is that there was only a small number of participants. The inclusion criteria focused on usage time rather than clinical symptoms. Thereby this study results may be difficult to generalize to other groups. Secondly, relatively short period of time for intervention, which were twice a week and 30 minutes each session would not have effectively induced psychological stabilization of the participants. Finally, there was a possibility that gaming time and cycle changes have been affected by external and environmental factors that may occur in school such as class hours and examination period. Therefore, in the future, these limitations must be considered by increasing the number of participants and intervention time to elicit more objective and generalized results.

This study investigated the effects of Snoezelen therapy on stress, depression, anxiety and quality of life of university students who overindulge computer games or mobile phone games. The study confirmed the possibility of Snoezelen therapy as a therapy method to induce effective responses in stress, depression, anxiety, and quality of life of university students with game addiction. Therefore, studies that apply Snoezelen to various groups to confirm positive effects based on this current study is recommended in the future.

\section{REFERENCES}

1. Ju HW, Bae SM. A psychological interview and test battery for record of internet addiction counseling. Korean Journal of Youth Studies. 2015; 22(5):231-54.

2. Shin SM, Ryu SJ, Kim BJ et al. The development and effectiveness of MI group counseling program for adolescents internet-addiction. JAPC. 2015;16(4):89-109.

3. Kwon MS, Nam KW, Seo BK. 2015 survey on internet over dependency. Ministry of Science and ICT.National Information Society Agency. 2016.

4. Kuss DJ. Internet gaming addiction: current perspectives. Psychology Res Behav Manag. 2013;6:125-37.

5. American Psychiatric Association. The diagnostic and statistical manual of mental disorders, 5th ed. Washington DC, Amer Psychiatric Pub Inc, 2013:795-8.

6. Kim EJ. The effect of depression, anxiety, stress on self-esteem and delinquency mediated internet game addiction of elementary students. The Journal of Elementary Education. 2015;28(3):95-122.

7. Lee JY, Park TW, Lee MS et al. Pattern of computer game play and emotional and behavioral characteristics in upper grade elementary school children. Anxiety and Mood. 2008;4(2):135-41.

8. Lee $\mathrm{CH}$, Jeong $\mathrm{GH}$. The relations between elementary pupils ' game addiction, aggression and personality. JKAIE. 2005;9(3):417-37.

9. Lee JH, Lee SJ, Chun JW et al. Comorbid depression interferes with emotional regulation in adolescents with internet gaming disorder. J Korean Neuropsychiatr Assoc. 2015;54(3):322-9.

10. Kim TH, Ha EH, Lee ES et al. Emotional and behavioral problems related with internet addiction in adolescence. J Korean Neuropsychiatr Assoc. 2005;44(3):364-70.

11. Kim YS, Kim SS, Lee SJ et al. Internet addiction and quality of life among some adolescents. Korean Juvenile Policy Association. 2014;25(25):3158.

12. Kim HJ. A case study on improving effect on internet game addiction behavior and self efficacy of children by play based cognitive behavior therapy. JSER. 2007;25(2):11-26.

13. Joo EH. A meta-analysis of the effects of music therapy for patients with addictive disorders. Sookmyung Women's University. Dissertation of Master's Degree. 2018.

14. Kim YS. The effect of self-control training on the internet game addiction of elementary school students. Daegu National University of Education. Dissertation of Master's Degree. 2004.

15. Han SK, Kim SH, Seo JB. The development of the game addiction remedy program based on scratch programming. JKAIE. 2010;14(1):61-8.

16. Lee GW, Lee HM, Shin JH. Effects of group art therapy on the aggression and emotional regulation ability of elementary school students over-immersed in internet games. Jour of KoCon A. 2016;16(9):769-78.

17. Kim NM, Park KE, Jang SE. Analysis of domestic research trends on positive psychological intervention for addiction recovery. Korean Counseling Association. 2018;19(1):113-28.

18. Kang SH. Effects of aerobic exercise on health-related quality of life (Peds $\mathrm{QL}^{\mathrm{m}}$ 4.0) and dopamine levels in adolescents with internet gaming addiction. The Korean Society of Sports Science. 2017;26(4):985-94.

19. Jun JH, Kang MY, Kim YH et al. Preference and expectation effectiveness of horticultural therapy programs for game and internet overindulgence of university students and young people. J People Plants Environ. 2017;20(3):73.

20. Ashby M, Lindsay WR, Pitcaithly D et al. Snoezelen: its effects on concentration and responsiveness in people with profound multiple handicaps. Br J Occup Ther. 1995;58(7):303-7.

21. Kewin J. Snoezelen: the reason and the method. In: Hutchinson \& Kewin J, eds, Sensations and disability: Sensory environments for leisure, snoezelen, education and therapy, Chesterfield, ROMPA, 1992;6-17.

22. Jamshidi Manesh M, Kalati M, Hosseini F. Snoezelen room and childbirth outcome: a randomized clinical trial. Iran Red Crescent Med J. 2015;17 (5):e18373.

23. Cox H, Burns I, Savage S. Multi sensory environments for leisure: promoting well-being in nursing home residents with dementia. J Gerontol Nurs. 2004;30(2):37-45.

24. Slevin E, Mcclelland A. Multisensory environments: are they therapeutic? a single-subject evaluation of the clinical effectiveness of a multisensory environment. J Clin Nurs. 1999;8(1):48-56.

25. Chitsey A, Haight B, Jones M. Snoezelen': a multisensory environmental intervention. J Gerontol Nurs. 2002;28(3):41-9.

26. Chae SG. A study on the effects of play based sensory integration treat- 
ment program on the behavior and sensory integration functions of children with developmental disorder. Journal of Play Therapy. 2007; 11(3):89-112.

27. Yong JH, Lee JY. The effects of multisensory environments (snoezelen) on the autonomic nervous system. Korean J of Occup Ther. 2006;14(3): 17-25.

28. Lee JY, Yoo EY. The effects of implementation of multisensory environments (snoezelen) on the emotional state of college students. Korean J of Occup Ther. 2006;14(2):39-47.

29. Baker R, Dowling Z, Wareing LA et al. Snoezelen: its long-term and shortterm effects on older people with dementia. Br J Occup Ther. 1997;60(5): 213-8.

30. Cohen S, Kamarck T, Mermelstein R. A global measure of perceived stress. J Health Soc Behav. 1983;24(4):385-96.

31. Cohen S, Williamson G. Perceived stress in a probability sample of the United States. In: Spacapan S \& Oskamp S, eds, The social psychology of health: Claremont symposium on applied social psychology. Sage, California, 1988;31-67.

32. Lee JE. The effects of self-complexity and self-efficacy on depression and perceived stress. Ajou University. Dissertation of Master's Degree. 2005.

33. Yoon SW, Lee BN, Park KH et al. Development of korean depression screening assessment : phase II preliminary validation study. Kor J Clin Psychol. 2018;37(2):252-62.

34. Pagnin D, de Queiroz V, Carvalho YT et al. The relation between burnout and sleep disorders in medical students. Acad Psychiatry. 2014;38(4): 438-44.

35. Kwon SM, Oei TP. Differential causal roles of dysfunctional attitudes and automatic thoughts in depression. Cognit Ther Res. 1992;16(3):30928.

36. Ware JE, Sherbourne CD. The MOS 36-item short-form health survey (SF-36): I. Conceptual framework and item selection. Med Care. 1992; 30(6):473-83.

37. Çelik D, Çoban Ö. Short form health survey version-2.0 turkish (SF36v2) is an efficient outcome parameter in musculoskeletal research. Acta Orthop Traumatol Turc. 2016;50(5):558-61.

38. Hong CK, Sin SY, Lee KH et al. Relationship between symptom scores and quality of life before and after endoscopic sinus surgery: comparison between RSDI and SF-36v2TM questionnaire. Korean J Otorhinolaryngol-Head Neck Surg. 2008;51(6):535-43.

39. Jeong HC. Internet and smartphone game addiction: a phenomenological comparison. AJMAHS. 2016;6(2):71-80.

40. Thompson SBN, Martin S. Making sense of multisensory rooms for people with learning disabilities. Br J Occup Ther. 1994;57(9):341-4.

41. Cuvo AJ, May ME, Post TM. Effects of living room, snoezelen room, and outdoor activities on stereotypic behavior and engagement by adults with profound mental retardation. Res Dev Disabil. 2001;22(3):183-204.

42. Burns I, Cox H, Plant H. Leisure or therapeutics? Snoezelen and the care of older persons with dementia. Int J Nurs Pract. 2000;6(3):118-26.

43. Jang C, Song MO, Bae JS et al. The effects of snoezelen on the stress and attention for college students. Journal of Korean Society of Health Science. 2008;5(1):57-74.

44. Seo HJ, Won JK, Jung YJ et al. The influence of snoezelen program on depression of college students: a prior study. Journal of Korean Society of Health Science. 2012;2(1):17-26. 